Eur. J. Clin. Chem. Clin. Biochem.

Vol. 30, 1992, pp. 745-751

(C) 1992 Walter de Gruyter \& Co.

Berlin $\cdot$ New York

\title{
Reference Limits of Plasma Fibrinogen
}

\author{
By P. Tarallo ${ }^{1}, J$. Henny ${ }^{1}$, R. Gueguen ${ }^{2}$ and G. Siest ${ }^{1}$
}

${ }^{1}$ Département de Biologie Clinique, URA CNRS 597

2 Département de Statistiques, Centre de Médecine Préventive, Vandoeuvre-les-Nancy, France

(Received December 5, 1991/June 17, 1992)

Summary: Fibrinogen is considered to be a strong predictor and independent factor of cardiovascular diseases.

The data presented here describe the baseline measurements of fibrinogen in 1008 apparently healthy subjects, aged 4-60 years and their relationship to age, sex, body weight, smoking, alcohol, and use of oral contraceptives. Pearson's correlations and a linear multiple regression model were used.

Plasma fibrinogen was measured kinetically in a photometer, the Behring Chromotimer, using the CTSfibrinogen method.

There were neither statistical difference between girls and boys aged 4-20 years nor correlation with variables related to cardiovascular diseases. In adults, we found an increase of plasma fibrinogen concentration with age and no statistical difference between men and women, except in subjects aged 40-50 years. There was a positive correlation between fibrinogen and ponderal index. In women aged $20-30,30-40,40-50$ and $50-60$ years, the mean fibrinogen concentrations increased of $0.009,0.021,0.010$ and $0.015 \mathrm{~g} / \mathrm{l}$ for one percent of overweight, in each subgroup respectively.

In women aged $20-30$ years using oral contraceptives, the mean fibrinogen concentration was $0.19 \mathrm{~g} / \mathrm{l}$ higher than in women not using oral contraceptives.

The smoking effect was observed only in 30-40 year-old men. Each cigarette smoked per day increases of the mean fibrinogen by $0.35 \mathrm{~g} / 1$ after standardization for ponderal index and alcohol consumption. Alcohol consumption was negatively correlated to plasma fibrinogen in subjects $30-40$ years old. In women, $1 \mathrm{~g}$ of alcohol per day induces a $0.008 \mathrm{~g} / 1$ decrease in the mean fibrinogen while in men the decrease is $0.004 \mathrm{~g} / \mathrm{l}$.

A correlation was found between fibrinogen and serum cholesterol $(p<0.001$ and $p<0.01$ for men and women, respectively) and fibrinogen and triacylglycerols $(p<0.05$ and $p<0.001$ for men and women, respectively). The known risk factors for cardiovascular diseases explained at most $15 \%$ of the total variance in fibrinogen concentrations among the studied population. Finally, reference limits according to age and sex are provided.

\section{Introduction}

Plasma fibrinogen, which is synthesized in the liver, is an essential blood coagulation factor. Its transformation into fibrin contributes to the formation of stable clots, and it is an essential cofactor in platelet aggregation. It increases plasma and blood viscosity and causes the aggregation of red cells, all of which reduce blood flow. It also plays a role in inflamma- tion, and its concentration in plasma increases in many non-specific situations. Fibrinogen and fibrin are also profoundly involved in atherogenesis $(1,2)$. As fibrinogen is involved in arteriosclerotic diseases and thrombosis, it may be a good predictor of cardiovascular diseases and major peripheral vascular diseases, as well as being an independent factor in these diseases. Various prospective studies (2-9), 
case-control studies $(10,11)$ and prevalence studies $(12,13)$ have shown that fibrinogen increases in subjects with cardiovascular diseases. The epidemiological Northwick Park heart study, in particular, showed that a fibrinogen value of one standard deviation (about $0.6 \mathrm{~g} / \mathrm{l})$ above the mean $(2.9 \mathrm{~g} / \mathrm{l})$ was associated with an $84 \%$ increase in the risk of an episode of ischaemic heart disease within 5 years (2). These data and the studies of Balleisen et al. $(14,15)$ associating fibrinogen with known risk factors of atherosclerosis led us to establish the reference limits for plasma fibrinogen in supposedly healthy subjects attending a preventive medicine centre for health screening.

We looked for any variations in fibrinogen concentration associated with certain cardiovascular risk factors (such as use of oral contraceptives, consumption of alcohol, smoking, ponderal index, blood pressure and serum cholesterol and triacylglycerols), studied the relationships between fibrinogen and these quantities and tried to account for the fibrinogen variation by means of a stepwise linear multiple regression.

\section{Materials and Methods}

\section{Participants}

We studied 1008 apparently healthy subjects (510 men and 498 women) aged $4-60$ years. Subjects suffering from an inflammatory reaction were identified and excluded if the erythrocyte sedimentation rate was $>20 \mathrm{~mm} / \mathrm{h}$ or if the C-reactive protein concentration measured by the immunolatex method in a Behring Nephelometer Analyser was $>10 \mathrm{mg} / \mathrm{l}$. None of the subjects was using any medication, except 109 women, aged $20-$ 30 years and $40-50$ years, who were taking oral contraceptive drugs. No women aged $30-40$ years taking oral contraceptives were selected.

\section{Methods}

Blood specimens were obtained by venipuncture from the cubital vein of fasting, supine subjects between 0800 and $0900 \mathrm{hr}$. Serum and citrated plasma were aliquoted and stored at $-20^{\circ} \mathrm{C}$, and analysed within 8 days of collection.

Plasma fibrinogen was measured kinetically in a photometer, the Behring Chromotimer. Citrated plasma was coagulated by the addition of a relatively large amount of thrombin. In an optimized buffer the increase in absorbance is directly proportional to the fibrinogen concentration. The results are given in grams per litre. The instrument and reagents (CTS-Fibrinogen Reagent) are manufactured by Behring Diagnostic Rueil-Malmaison, France. Day-to-day controls were tested using CTScontrol plasma (Behring). The within-run variation was $5.5 \%$ $(\mathrm{n}=21, \mathrm{~m} \pm \mathrm{SD}=2.00 \pm 0.11 \mathrm{~g} / \mathrm{l})$.

To evaluate preanalytical variation, we studied samples stored at $4{ }^{\circ} \mathrm{C}$ for 24 or 48 hours, and at $-20^{\circ} \mathrm{C}$ for 1,2 or 8 days. There was no statistically significant difference between plasma fibrinogen values measured at day 0 and those measured after 1 or 2 days storage at $4{ }^{\circ} \mathrm{C}$ or after 1,2 or 8 days storage at $-20^{\circ} \mathrm{C}$. These results are in agreement with the recommendations of the National Committee for Clinical Laboratory Standards (NCCLS), which permit citrated plasma to be frozen and stored at $-20^{\circ} \mathrm{C}$ for more than 8 days (16).
Serum cholesterol and triacylglycerols were measured by enzymatic methods [CHOD-PAP and GPO-PAP, respectively (Merck, Darmstadt 1, Germany)] on an Olympus Au 5010 (Olympus Biologie, 94150 Rungis, France).

Height in stocking feet and weight in light clothing were measured. The ponderal index was calculated according to the Lorentz formula $(17,18)$ : (measured weight/theoretical ideal weight) $\times 100$; the theoretical ideal weight $(\mathrm{kg})$ depending on the height $(\mathrm{H} \mathrm{cm})$ was calculated from the following equations: $(\mathrm{H}-100)-(\mathrm{H}-150) / 4$ for men; and $(\mathrm{H}-105)-(\mathrm{H}-$ 150)/4, for women.

Systolic and diastolic blood pressures were measured using a mercury sphygmomanometer with appropriate-sized cuffs on the left arm of supine subjects after a five minute test. One reading was taken and used for analysis.

Smoking habits and alcohol intake were known from a questionnaire which the patients answered. Subjects smoking less than 5 cigarettes (or pipe or cigar equivalents) per day or drinking less than $22 \mathrm{~g}$ of alcohol daily were considered as nonsmokers or non-drinkers.

\section{Statistical evaluation}

Student's t-test and Bartlett's test were used to determine differences in mean values and to analyse the variances, respectively; Pearson's correlation was used to test the linear relationship between fibrinogen and the following variables: age, weight, ponderal index, systolic and diastolic blood pressure, alcohol (g/day) and cigarette (g/day) consumption, use of oral contraceptives and serum total cholesterol and triacylglycerols. A linear multiple regression model was used to test the independent influence of these variables on fibrinogen concentration (19).

\section{Results}

\section{Population distribution}

A $\chi^{2}$-test showed that the hypothesis of a Gaussian distribution of plasma fibrinogen within each age group $(4-14,14-20,20-30,30-40,40-50$ and $50-60)$ and each sex was acceptable.

\section{Age and sex}

The Student's t-test shows that there was no statistical difference between the sexes except in subjects aged $40-50$ years [mean $\pm \mathrm{SD}$ for men $=2.99 \pm 0.59 \mathrm{~g} / \mathrm{l}$ $(\mathrm{n}=125)$ versus $2.81 \pm 0.50 \mathrm{~g} / \mathrm{l}$ for women $(\mathrm{n}=90)$, $\mathrm{p}=0.017]$. The analysis of variances between each age group (for men or for women) shows that there was no statistical difference between the variances, but there were statistical differences between the means (for men $\mathrm{F}=6.761, \mathrm{p}<0.001$; for women $\mathrm{F}=3.829, \mathrm{p}<0.003)$. Fibrinogen was higher in children and adolescents than in adults aged $20-30$ years. There were statistically significant differences between children (both girls and boys) aged 4-14 years and adults aged $20-30$ years, for example: boys $(\mathrm{n}=54)$, mean $\pm \mathrm{SD}=3.07 \pm 0.57 \mathrm{~g} / \mathrm{l}$; men $(\mathrm{n}=109), 2.65 \pm 0.52 \mathrm{~g} / \mathrm{l} ; \mathrm{p}<0.001$. From age 30, plasma fibrinogen increased steadily in both women and men. 
Using fibrinogen concentration as the dependent variable, a stepwise multiple linear regression model was performed for men and women aged 4-14, 14-20, $20-30,30-40,40-50$ and $50-60$ years.

In both male and female children, no tested variable affected the fibrinogen concentration.

\section{Smoking}

In adults, a significant effect of smoking appeared only in men aged $30-40$ years. Each cigarette smoked per day increased the mean fibrinogen by $0.35 \mathrm{~g} / \mathrm{l}$ after standardization for ponderal index and alcohol consumption. In men aged 20-50 years smoking more than 10 cigarettes per day, the fibrinogen concentration was higher $(+0.19 \mathrm{~g} / \mathrm{l})$ than in non-smokers. Thus, fibrinogen varied from $2.785 \mathrm{~g} / 1 \pm 0.564$ (mean $\pm \mathrm{SD})$ in non-smokers $(n=163)$ to 2.974 \pm 0.615 (mean $\pm S D)$ in men $(n=119)$ smoking more than 10 cigarettes per day.

\section{Alcohol consumption}

The effects of alcohol consumption were studied in subjects $30-40$ years old. In women, $1 \mathrm{~g}$ of alcohol per day induced a $0.008 \mathrm{~g} / 1$ decrease in the mean fibrinogen concentration after standardization for weight and use of oral contraceptives. The fibrinogen varied from $2.936 \mathrm{~g} / 1 \pm 0.415$ (mean $\pm \mathrm{SD}$ ) in women who drank less than $22 \mathrm{~g}$ of alcohol per day $(\mathrm{n}=44)$ to $2.670 \mathrm{~g} / \mathrm{l} \pm 0.347$ in women $(\mathrm{n}=8)$ drinking more than $22 \mathrm{~g} / \mathrm{d}$ of alcohol. In men, after standardization for ponderal index and cigarette consumption, the decrease was $0.004 \mathrm{~g} / 1$ for $1 \mathrm{~g}$ of alcohol per day.

\section{Overweight}

Regression analysis showed that the fibrinogen concentration increased by $0.1,0.21,0.1$ and $0.15 \mathrm{~g} / \mathrm{l}$ per $10 \%$ overweight for women aged $20-30,30-40$, $40-50$ and 50-60 years, respectively. In men, overweight affected the fibrinogen concentration only in subjects aged 30-40 and 50-60 years (increases of 0.10 and $0.14 \mathrm{~g} / \mathrm{l}$, respectively, per $10 \%$ of overweight).

\section{Use of oral contraceptives}

The influence of oral contraceptives on the fibrinogen concentration was evaluated only in women aged $20-$ 30 and $40-50$ years. In the younger group, the mean fibrinogen concentration of women taking oral contraceptives was significantly $(0.19 \mathrm{~g} / \mathrm{l})$ higher, weight for weight, than in the women not taking them. The fibrinogen concentrations were $2.707 \mathrm{~g} / \mathrm{l}( \pm 0.444)$ in 75 women without oral contraception, aged $20-30$ years with a ponderal index between $70-130$, and $2.921 \mathrm{~g} / \mathrm{l}( \pm 0.564)$ in 88 women of the same age and using oral contraceptives. In the women $40-50$ years old, too few women were taking oral contraceptives, so that the results were not statistically significant.

\section{Correlations and multivariate analysis}

The table 1 shows the coefficients of correlation between fibrinogen and the biological variables associated with cardiovascular risk in subjects aged $20-60$ years. The plasma fibrinogen concentration was positively correlated with age, weight, ponderal index, and serum total cholesterol and triacylglycerols in subjects of both sexes, with systolic and diastolic blood pressure in women only, and with cigarette consumption in men; it was negatively correlated with alcohol consumption in women.

Tab. 1. Correlation coefficients between plasma fibrinogen and selected cardiovascular disease risk factors in subjects aged $20-60$ years

\begin{tabular}{lll}
\hline & Men & Women \\
\hline Age & $0.275^{* * *}$ & $0.139 * *$ \\
Weight & $0.144^{* * *}$ & $0.284^{* * *}$ \\
Systolic blood pressure & $\mathrm{NS}$ & $0.130^{*}$ \\
Diastolic blood pressure & $\mathrm{NS}$ & $0.123^{*}$ \\
Ponderal index & $0.226^{* * *}$ & $0.337^{* * *}$ \\
Alcohol consumption & $\mathrm{NS}$ & $-0.102^{*}$ \\
Cigarettes consumption & $0.100^{*}$ & $\mathrm{NS}$ \\
Oral contraceptives & - & $\mathrm{NS}$ \\
Serum cholesterol & $0.209^{* * *}$ & $0.156^{* *}$ \\
Serum triacylglycerols & $0.116^{*}$ & $0.228^{* * *}$ \\
\hline$* * *$ & & \\
\hline
\end{tabular}

${ }^{* * *} \mathrm{p}<0.001{ }^{* *} \mathrm{p}<0.01{ }^{*} \mathrm{p}<0.05$, NS not significant

The results of the stepwise multiple linear regression model performed for adults aged $20-60$ years are summarized in table 2 . The regression coefficient corresponds to the change in fibrinogen concentration associated with one unit change in the variable; this accounts for $13.9 \%$ and $15 \%$ of the total variance in men and women, respectively.

\section{Reference limits}

Reference limits were established according to the recommendations of the International Federation of Clinical Chemistry (20) and the Societé Française de Biologie Clinique (21), using the following exclusion and partition criteria. Exclusion criteria: non-fasting state, overweight (ponderal index $>120$ ), use of drugs 
Tab. 2. Results of a stepwise multiple regression of plasma fibrinogen $(\mathrm{g} / \mathrm{l})$ in relation to other cardiovascular risk factors in subjects aged $20-60$ years

\begin{tabular}{lcc}
\hline & Men $(\mathrm{n}=378)$ & Women $(\mathrm{n}=377)$ \\
\hline Variables & Regression coefficient (SE) & Regression coefficient (SE) \\
\hline Age (years) & $0.0132(0.0029)^{* * *}$ & - \\
Systolic blood pressure mmHg & - & - \\
Diastolic blood pressure mmHg & - & - \\
Ponderal Index (\%) & $0.0049(0.0021)^{*}$ & $0.0092(0.0016)^{* * *}$ \\
Alcohol consumption (g/day) & $-0.0023(0.0007)^{* *}$ & $-0.0060(0.0020)^{* *}$ \\
Cigarettes consumption (g/day) & $0.0061(0.0018)^{* * *}$ & - \\
Use of contraceptives & - & - \\
Serum cholesterol (mmol/l) & $0.0493(0.0221)^{*}$ & - \\
Serum triacylglycerols (mmol/l) & - & $0.1506(0.0487)^{* *}$ \\
& Intercept: 1.543 & Intercept: 1.792 \\
\end{tabular}

*** $\mathrm{p}<0.001 ;{ }^{* *} \mathrm{p}<0.01 ;^{*} \mathrm{p}<0.05 ;-$ : not significant; SE: standard error

and/or oral contraceptives, cigarette consumption more than 5 per day and alcohol intake higher than 22 g per day. Partition criteria: age, sex.

The estimates of percentiles 5 and 95, assuming a Gaussian distribution, are given in table 3.

\section{Discussion}

Fibrinogen concentrations were higher in children and adolescents than in adults aged $20-30$ years. Although published reports offer no explanation of this difference, it may be related to growth.

Like other authors $(14,22,23)$, we found an increase of fibrinogen concentration with age in adults but no statistical difference between the sexes. Lee et al. (9), in contrast, found higher fibrinogen concentrations in women than in men $(p<0.001)$.

The positive relationships between fibrinogen concentrations and the body-weight or ponderal index were statistically significant in both males and females, as in the Northwick Park study (22) and the Münster arteriosclerosis study (14), in which skinfold thickness or the Broca index, respectively, was used.
Women aged $20-30$ years taking oral contraceptives had higher fibrinogen concentrations than those not taking them $(p<0.01)$. The difference between those using and not using oral contraceptives disappeared in women aged $40-50$ years, and we did not observe any relationship between fibrinogen concentration and oral contraceptive use in women aged $20-60$ years considered as a single group. The small number of subjects might explain these discrepancies, because epidemiological studies $(14,24,25)$ have shown that the use of oral contraceptives greatly increases the fibrinogen concentration: from 0.18 (14) to 0.35 (24) or $0.4 \mathrm{~g} / 1(25)$. The use of oral contraceptives induced not only an increase of fibrinogen concentration but also an increase of factors VII and X and a decrease of antithrombin III concentrations. These changes, together with the rise of triacylglycerols and blood pressure would all be expected to favour thrombosis (24).

The biological variability of fibrinogen in healthy subjects during one day was estimated to be $3.5 \%$ but it may attain $13.0 \%$. Over 6 months, this intraindividual variability reached $10 \%$ to $18.9 \%$ (26). Other authors (27) have reported intra-individual var-

Tab. 3. Reference limits of plasma fibrinogen ( $\mathrm{g} / \mathrm{l})$ according to age and sex.

Number of patients (n), mean ( $\overline{\mathrm{x}})$, standard deviation (SD) and estimated percentiles (5 and 95) are given

\begin{tabular}{|c|c|c|c|c|c|c|c|c|c|c|}
\hline \multirow{3}{*}{ Age (years) } & \multicolumn{5}{|c|}{ Men } & \multicolumn{5}{|c|}{ Women } \\
\hline & \multirow[t]{2}{*}{$\mathrm{n}$} & \multirow[t]{2}{*}{$\overline{\mathrm{x}}$} & \multirow[t]{2}{*}{$\mathrm{SD}$} & \multicolumn{2}{|c|}{ Percentiles } & \multirow[t]{2}{*}{$\mathrm{n}$} & \multirow[t]{2}{*}{$\overline{\mathbf{x}}$} & \multirow[t]{2}{*}{ SD } & \multicolumn{2}{|c|}{ Percentiles } \\
\hline & & & & 5 & 95 & & & & 5 & 95 \\
\hline $4-14$ & 54 & 3.07 & 0.57 & 2.13 & 4.01 & 52 & 2.94 & 0.46 & 2.18 & 3.70 \\
\hline $14-20$ & 55 & 2.85 & 0.46 & 2.09 & 3.61 & 56 & 2.94 & 0.45 & 2.20 & 3.68 \\
\hline $20-30$ & 109 & 2.65 & 0.52 & 1.80 & 3.50 & 75 & 2.71 & 0.44 & 1.99 & 3.43 \\
\hline $30-40$ & 33 & 2.77 & 0.49 & 1.96 & 3.58 & 43 & 2.85 & 0.37 & 2.24 & 3.46 \\
\hline $40-50$ & 125 & 2.99 & 0.59 & 2.02 & 3.96 & 90 & 2.81 & 0.50 & 1.99 & 3.63 \\
\hline $50-60$ & 51 & 2.89 & 0.47 & 2.12 & 3.66 & 41 & 3.05 & 0.46 & 2.29 & 3.81 \\
\hline
\end{tabular}


iation of $26 \%$ or $41 \%$ over 5 years. Thus "the capability for detecting a difference between two groups will depend to a large extent on its magnitude. The smaller this is the larger the number of observations required for its demonstration" (27).

In our study, a slight effect of smoking on the fibrinogen concentration was seen only in men. These findings are consistent with those of other authors $(7-9,14,23,28)$, who, however, also found an effect in women. There is some evidence of a dose-response effect of smoking on fibrinogen (9). The smoking cessation and the adoption or resumption of smoking were associated with a decrease or an increase, respectively, of about $0.15 \mathrm{~g} / 1$ in plasma fibrinogen. These changes would lower or raise the risk of ischaemic heart disease by about $20 \%$ (29).

In our study, a slight negative correlation between alcohol intake and fibrinogen was found only in women. However, a linear multiple regression analysis showed a significant negative effect of alcohol in both sexes $(p<0.05)$. Other authors $(9,24)$ have found that non-drinkers of both sexes have higher fibrinogen concentrations than drinkers ( $p<0.001$ ), even after standardization for smoking. In contrast, the Münster arteriosclerosis study did not show a significant correlation (14).

The plasma fibrinogen concentration is correlated with other risk factors of cardiovascular disease, such as blood pressure and serum total cholesterol and triacylglycerols. Our results showed a positive relationship between fibrinogen and blood pressure, in women only, as in other studies $(9,15)$. Some authors $(4,6-8)$, however, have found a correlation in men too $(p<0.05$ to $p<0.001)$. Like others $(9,15)$, we have also seen a positive relationship between fibrinogen and cholesterol or triacylglycerols. Nevertheless, in the stepwise multiple regression analysis of plasma fibrinogen in relation to other variables, serum cholesterol appears only in men $(p<0.05)$ and triacylglycerols in women $(p<0.01)$, all aged $20-60$ years.

Recently, Landin et al. (30) found that fibrinogen concentrations in hypertensive patients were $18 \%$ higher $(p<0.05)$ than in normotensive subjects of the same age, bodyweight and height. This increase was associated with increased cholesterol, triacylglycerols, glucose, plasma insulin, plasminogen activator inhibitor (PAI-1) (30), globulin, albumin, total protein and plasma viscosity (31). Stone \& Thorp's prospective study (6) of 297 men aged 40-69 years observed for a mean period of 7 years showed that in men with high cholesterol or high systolic blood pressure, the incidence of heart attacks was respectively 6 times and 12 times greater in those with high plasma fibrinogen concentrations $(>3.5 \mathrm{~g} / \mathrm{l})$ than in those with low fibrinogen concentration.

The results of the multivariate analysis are essentially the same in men and in women and do not account for the sex differences in cardiovascular morbidity. Only a small percentage of the fibrinogen variation can be explained by the factors previously cited. Other factors may have very important effects.

Sex-related factors such as pregnancy or postmenopausal status induce large fibrinogen variations. It increases by $60 \%$ until the 37 th week of gestation, then decreases at 8 weeks postpartum $(p<0.05)(37)$. In postmenopausal women, plasma fibrinogen is higher than in premenopausal women of the same age $(\mathrm{p}<0.01)(9)$.

Genetic variations were described by Humphries et al. (32), who found mean fibrinogen concentrations of $2.74,3.69$ and $2.98 \mathrm{~g} / 1$ in subjects with genotypes $\mathrm{B}_{1} \mathrm{~B}_{1}, \mathrm{~B}_{2} \mathrm{~B}_{2}$ and $\mathrm{B}_{1} \mathrm{~B}_{2}$ respectively. Polymorphism accounted for $15 \%$ of the total variation of fibrinogen. Other authors (33) found that $51 \%$ of the variance of plasma fibrinogen concentration was accounted for by genetic heritability. Iso et al. (34) found also that mean plasma fibrinogen concentrations are $16 \%$ to $30 \%$ lower in Japanese men than in Caucasian men $(p<0.001)$. This lower plasma fibrinogen concentration may be partially attributable to differences in environmental factors. Diet, in particular, seems to affect fibrinogen concentrations considerably. For example, supplementation with fish oil and corn oil ( $\omega-3$ and $\omega-6$ polyunsaturated fatty acids) for 8 weeks is associated with $10 \%$ to $13 \%$ reductions of plasma fibrinogen concentrations $(p<0.01)$ in patients with hyperlipoproteinaemia types IIb or IV. Such supplementation, particularly with fish oil, therefore seems to have a beneficial "antithrombotic" effect (35). Kromhout et al. (36) observed an inverse dose-response relation between fish consumption and death from coronary heart disease during 20 years follow-up in a group of Dutchmen.

The fibrinogen concentration also varies seasonally. It is up to $7 \%$ higher in summer ( 3.85 and $3.91 \mathrm{~g} / 1$ in July and August, respectively) than in winter ( $3.65 \mathrm{~g} / 1$ in January) in healthy male blood donors (38).

Noise, infrasounds, vibrations and electromagnetic fields all affect plasma fibrinogen concentrations. Healthy men exposed to intense infrasounds, acoustic noise and airborne dust during 2 to 15 years for $6-8$ hours per day, had $31 \%$ higher plasma fibrinogen concentrations than control men of the same age (39). 
Other authors (40) found that plasma fibrinogen concentrations were $15 \%$ higher in men in lower grades of employment than in those in higher grades (means $3.39 \mathrm{~g} / \mathrm{l}$ and $2.95 \mathrm{~g} / \mathrm{l}$, respectively; $\mathrm{p}<0.01$ ) but did not find such differences in other haemostatic variables.

Plasma fibrinogen is subject to distinct physiological variations but also to pathological variations during the acute phase of the inflammatory reaction, diabetes, malignant diseases and cardiovascular diseases. In the acute-phase reaction, the plasma fibrinogen concentration is at least $50 \%$ higher than normal. After the tissular aggression, it increases slowly, showing an appreciable change after 24 hours, in contrast to $C$-reactive protein, which evolves rapidly (6 hours) (41). Some drugs can also alter its concentration. Pentoxifylline (Torental $400^{\circledR}$ ) given to patients with vascular disease or those with a high risk of thrombosis (due to diabetes or arteritis) significantly lowers plasma fibrinogen concentrations (by $18 \%$ to $20 \%$ ) after a month of treatment $(42,43)$. The same effect is obtained with bezafibrate $\left(\right.$ Befizal $^{\mathrm{R}}$ ) in patients with insulin-dependent diabetes (44), in whom a $20 \%$ decrease is observed after the first month of treatment, as well as a decrease of cholesterol and triacylglycerols.

\section{References}

1. Smith, E. B. (1986) Fibrinogen, fibrin and fibrin degradation products in relation to atherosclerosis. Clin. Haematol. $15,355-370$

2. Meade, T. W., Brozovic, M., Chakrabarti, R. R., Haines, A. P., Imeson, J. D., Mellows, S., Millre, G. J., North, W. R. S., Stirling, Y. \& Thompson, S. G. (1986) Haemostatic function and ischaemic heart disease: principal results of the Northwick Park Heart Study. Lancet 2, 533-537.

3. Meade, T. W., Chakrabarti, R., Haines, A. P., North, W. R. S., Stirling, Y., Thompson, S. G. \& Brozovic, M. (1980) Haemostatic function and cardiovascular death: early results of a prospective study. Lancet $1,1050-1053$.

4. Wilhelmsen, L., Svärdsudd, K., Korsan-Bengtsen, K., Larsson, L., Welin, L. \& Tibblin, G. (1984) Fibrinogen as a risk factor for stroke and myocardial infarction. N. Engl. J. Med. 311, 501-505.

5. Welin, L, Svärdsudd, K., Wilhelmsen, L., Larsson, B. \& Tibblin, G. (1987) Analysis of risk factors for stroke in a cohort of men born in 1913. N. Engl. J. Med. 317, 521 526.

6. Stone, M. C. \& Thorp, J. M. (1985) Plasma fibrinogen a major coronary risk factor. J. Royal College of General Practitioners. 35, 565-569.

7. Kannel, W. B., D'Agostino, R. B. \& Belanger, A. J. (1987) Fibrinogen, cigarette smoking, and risk of cardiovascular disease: Insights from the Framingham study. Am. Heart J. 113, 1006-1010.

8. Kannel, W. B., Wolf, P. A., Castelli, W. P. \& D'Agostino, R. B. (1987) Fibrinogen and risk of cardiovascular disease. The Framingham study. J. Am. Med. Assoc. 258, 11831186.
In this report we show that carefully defined reference limits are needed for the interpretation of plasma fibrinogen concentrations. Data from the literature and our own results clearly show that these limits must be improved. Analytical and preanalytical factors must be minimized by standardization of blood sampling (exclusively on citrate; clotted, haemolysed or lipaemic blood specimens should be discarded). If samples cannot be analysed within 4 hours of collection, citrated plasma must be frozen and stored at $-20^{\circ} \mathrm{C}$. Analytical variation must also be decreased by using automatic analysers and performing all tests at $37 \pm 1{ }^{\circ} \mathrm{C}$. Finally, the following important biological factors must be taken into account: age, sex, ponderal index, hormonal status (menopause), blood pressure, pregnancy, alcohol and smoking habits, oral contraceptive or drug intake and genetic and cultural inheritance.

\section{Acknowledgement}

This work was supported by a grant from the Caisse d'Assurance Maladie and by Behring Diagnostic (260, Avenue Napoléon Bonaparte, B. P. 237, 92504 RUEIL-MAL-MAISON CEDEX, FRANCE), which kindly provided the fibrinogen and CRP kits and the Chromotimer analysers.

9. Lee, A. J., Smith, W. C. S., Lowe, G. D. O. \& TunstallPedoe, H. (1990) Plasma fibrinogen and coronary risk factors: the Scottish Heart Health Study. J. Clin. Epidem. 43, 913-919.

10. Hamsten, A., Blombäck, M., Wiman, B., Svensson, J., Szamosi, A., de Faire, U. \& Mettinger, L. (1986) Haemostatic function in myocardial infarction. Br. Heart J. 55, $58-66$.

11. Lowe, G. D. O., Drummond, M. M., Lorimer, A. R., Hutton, I., Forbes, C. D., Prentice, C. R. M. \& Barbenel, J. C. (1980) Relation between extent of coronary artery disease and blood viscosity. Br. Med. J. 280, 673-674.

12. Baker, I. A., Eastham, R., Elwood, P. C., Etherington, M., O’Brien, J. R. \& Sweetnam, P. M. (1982) Haemostatic factors associated with ischaemic heart disease in men aged 45 to 64 years. The Speedwell Study. Br. Heart J. 47, 490494.

13. Yarnell, J. W. G., Baker, I. A., Sweetnam, P. M., Bainton, D., O'Brien, J. R., Whitehead, P. J. \& Elwood, P. C. (1991) Fibrinogen, viscosity and white blood cell count are major risk factors for ischaemic heart disease. The Caerphilly and Speedwell collaborative heart disease studies. Circulation $83,836-844$.

14. Balleisen, L., Bailey, J., Epping, P. H., Schulte, H. \& van de Loo, J. (1985) Epidemiological study on factor VII, factor VIII and fibrinogen in an industrial population: I. Baseline data on the relation to age, gender, body-weight, smoking, alcohol, pill-using, and menopause. Thromb. Haemostas. 54, 475-479. 
15. Balleisen, L., Assmann, G., Bailey, J., Epping, P. H., Schulte, H. \& van de Loo, J. (1985) Epidemiological study on factor VII, factor VIII and fibrinogen in an industrial population. II. Baseline data on the relation to blood pressure, blood glucose, uric acid, and lipid fractions. Thromb. Haemostas. 54, 721 - 723 .

16. Gralnick, H. R., Huseby, R. M., Evatt, B. L., Roberts, H., Gray, A. \& Triplett, D. A. (1982) Proposed guidelines for a standardized procedure for the determination of fibrinogen in biological samples. NCCLS 2, 409-422.

17. Lorentz, F. H. (1929) Ein neuer Konstitutionsindex. Klin. Wochenschr. 16, 348-351.

18. Lorentz, F. H. (1929) Der Konstitutionsindex der Frau. Klin. Wochenschr. 16, 734-736.

19. Sookne, D. \& Forsythe, A. (1988) t tests. In: BMDP Statistical Software (Dixon, W. J., Brown, M. B., Engelman, L., Hill, M. A. \& Jenrich, R. I., eds.) University of California Press, Berkeley 1,143-159.

20. Petitclerc, C. \& Wilding, P. (1984) The theory of reference values. Part 2. Selection of individuals for the production of reference values. Clin. Chim. Acta 139, 205F-213F; J. Clin. Chem. Clin. Biochem. 22, 203-208.

21. Siest, G. \& Henny, J. (1981) Production des valeurs de référence de sujets sains. Document G. Ann. Biol. Clin. 39, 235-244.

22. Meade, T. W., Chakrabarti, R., Haines, A. P., North, W. R. S. \& Stirling, Y. (1979) Characteristics affecting fibrinolytic activity and plasma fibrinogen concentrations. Br. Med. J. 1, 153-156.

23. Berglund, U., Wallentin, L. \& von Schenck, H. (1988) Platelet function and plasma fibrinogen and their relations to gender, smoking habits, obesity and $\beta$-blocker treatment in young survivors of myocardial infarction. Thromb. Haemostas. 60, $21-24$.

24. Meade, T. W., Brozovic', M., Chakrabarti, R., Howarth, D. J., North, W. R. S. \& Stirling, Y. (1976) An epidemiological study of haemostatic and other effects of oral contraceptives. Br. J. Haematol. 34, 353-364.

25. Wahlberg, T. B., Blombäck, M. \& Magnusson, D. (1984) Influence of sex, blood group, secretor character, smoking habits, acetylsalicylic acid, oral contraceptives, fasting and general health state on blood coagulation. Variables in randomly selected young adults. Haemostasis 14, 312319.

26. Costongs, G. M. P. J., Bas, B. M., Janson, P. C. W., Hermans, J., Brombacher, P. J. \& van Wersch, J. W. J. (1985) Short-term and long-term intra-individual variations and critical differences of coagulation parameters. J. Clin. Chem. Clin. Biochem. 23, 405-410.

27. Meade, T. W., North, W. R. S., Chakrabarti, R., Haines, A. P. \& Stirling, Y. (1977) Population-based distributions of haemostatic variables. Br. Med. Bull. 3, 283-288.

28. Chao, F. C., Tullis, J. L., Alper, C. A., Glynn, R. J. \& Silbert, J. E. (1982) Alteration in plasma proteins and platelet functions with aging and cigarette smoking in healthy men. Thromb. Haemostas. 47, 259-264.

29. Meade, T. W., Imeson, J. \& Stirling, Y. (1987) Effects of changes in smoking and other characteristics on clotting factors and the risk of ischaemic heart disease. Lancet 2 , 986-988.
30. Landin, K., Tengborn, L. \& Smith, U. (1990) Elevated fibrinogen and plasminogen activator inhibitor (PAI-1) in hypertension are related to metabolic risk factors for cardiovascular disease. J. Int. Med. 227, 273-278.

31. Letcher, R. L., Chien, S., Pickering, T. G., Sealey, J. E. \& Laragh, J. H. (1981) Direct relationship between blood pressure and blood viscosity in normal and hypertensive subjects. Role of fibrinogen and concentration. Am. J. Med. 70, 1195-1202.

32. Humphries, S. E., Cook, M., Dubowitz, M., Stirling, Y. \& Meade, T. W. (1987) Role of genetic variation at the fibrinogen locus in determination of plasma fibrinogen concentrations. Lancet $1,1452-1455$.

33. Hamsten, A., Iselius, L., de Faire, U. \& Blombäck, M. (1987) Genetic and cultural inheritance of plasma fibrinogen concentration. Lancet 2, 988-991.

34. Iso, H., Folsom, A. R., Wu, K. K., Finch, A., Munger, R. G., Sato, S., Shimamoto, T., Terao, A. \& Komachi, Y. (1989) Hemostatic variables in Japanese and caucasian men. Plasma fibrinogen, factor VIIc, factor VIIIc, and Von Willebrand factor and their relations to cardiovascular disease risk factors. Am. J. Epidemiol. 130, 925-934.

35. Radack, K., Deck, C. \& Huster, G. (1990) The comparative effects of $\omega-3$ and $\omega-6$ poly-unsaturated fatty acids on plasma fibrinogen levels: a controlled clinical trial in hypertriglyceridemic subjects. J. Am. College Nutrition 9, $352-357$.

36. Kromhout, D., Bosschieter, E. B. \& de Lezenne Coulander, C. (1985) The inverse relation between fish consumption and 20-year mortality from coronary heart disease. N. Engl. J. Med. 312, 1205-1209.

37. Huisman, A., Aarnoudse, J. G., Heuvelmans, J. H. A., Goslinga, H., Fidler, V., Huisjes, H. J. \& Zijlstra, W. G. (1987) Whole blood viscosity during normal pregnancy. Br. J. Obstet. Gynaecol. 94, 1143-1149.

38. Tromp, S. W. (1972) Influence of weather and climate on the fibrinogen content of human blood. Int. J. Biometeor. 16, $93-95$.

39. Polanowska, R. \& Cierniewski, C. S. (1987) Activation of blood platelets and increased plasma fibrinogen and fibronectin and men exposed to infrasounds, acoustic noise and air-borne dust in electric steelworks. Thromb. Res. 48, $363-371$.

40. Markowe, H. L. J., Marmot, M. G., Shipley, M. J., Bulpitt, C. J., Meade, T. W., Stirling, Y., Vickers, M. V. \& Semmence, A. (1985) Fibrinogen: a possible link between social class and coronary heart disease. Br. Med. J. 291, 13121314.

41. Engler, R. (1988) Données récentes sur les protéines de la réaction inflammatoire. In: XIIe Journées Nationales de Biologie, Grenoble 15-16/1/1988, Les nouveaux marqueurs protéiques, pp. $7-15$.

42. Soria, J. \& Soria, C. (1989) Biologie du fibrinogène. Place de la pentoxifylline. J. Mal. Vascul. 14, 25-28.

43. Soria, J., Lancrenon, S. \& Chassoux, G. (1989) Fibrinogène et pentoxifylline. Resultats d'une étude comparative française exploratoire de l'artérite au stade II. J. Mal. Vascul. 14, 29-34.

44. Durrington, P. N., Winocour, P. H. \& Bhatnagar, D. (1990) Bezafibrate retard in patients with insulin-dependent diabetes: effect on serum lipoproteins, fibrinogen and glycemic control. J. Cardiovasc. Pharmacol. 16, S30-S34.

Dr. J. Henny

Département de Biologie Clinique 2, Avenue du Doyen Jacques Parisot F-54500 Vandœuvre-les-Nancy France 
